\title{
Internet of Things-based Street Lighting System with Message Queuing Telemetry Transport and Progressive Web Application
}

\author{
DOI:10.36909/jer.ASSEEE.16097
}

\author{
H Irmayanti*, T Tosin** M L Mahdi***, B Yosafat**** \\ ***,***Departement Teknik Komputer, Universitas Komputer Indonesia, Indonesia \\ **** Departemen Teknik Informatika, Universitas Komputer Indonesia, Indonesia \\ * Corresponding Author: haniirmayanti@email.unikom.ac.id.
}

\begin{abstract}
The purpose of this study is to implement the Message Queuing Telemetry Transport (MQTT) protocol and the Progressive Web App (PWA) of the Internet of Things (IoT) based public street lighting system. The MQTT (Message Queuing Telemetry Transport) protocol is a protocol that runs on the TCP / IP stack and is specially designed for machine to machine that does not have a special address. Progressive web application (PWA) is a software creation method by combining regular websites with mobile \& desktop applications. This research is a development from previous research on Automatic Public Street Lighting. The development carried out includes a communication system, monitoring of lighting conditions, and automation or manual control of lights. The results obtained are the ease of monitoring lamp conditions and early detection of lamp problems. These results are obtained from the data sent by each street light, in the form of lamp status data, voltage, and electric current, through Long Range (LoRa) communication to the gateway using a radio network. The gateway data is then sent to the broker via the internet using the MQTT protocol and control and monitoring street light conditions using the Real-time Website and a mobile device. This research's impact is that street lighting monitoring and maintenance can be carried out more efficiently.
\end{abstract}




\section{INTRODUCTION}

Public street lighting is usually installed on trees or certain places such as parks and other public places that are public and are used for common interests (Buwana et al., 2018). Its use requires electrical energy as a source of power. The power source can use solar panels to save energy and reduce CO 2 emissions (Aung, N. S. M., \& Myint, Z. H. 2015). Regular monitoring is required to ensure the street lights are functioning properly. An efficient system is needed to assist officers in monitoring lamp conditions. One of the technologies that can be applied is the internet of things. Internet of Things (IoT) is a global network with a dynamic infrastructure that can connect physical attributes and virtual personalities with communication protocols using smart interfaces into an information network (Ray, P. P. 2018). The communication protocol applied in connecting things to the internet is Message Queuing Telemetry Transportation (MQTT). MQTT is a public-subscribed-based protocol that can be applied to the internet because of its advantages, including being easy to implement on various embedded systems, being open-source, and saving power usage (Tang et al., 2013). The website becomes a choice in the user interface. The website here can monitor the condition and location of the lights and control the lights' work. However, it is also necessary to create a website that can run lightly on mobile devices for easy on-site monitoring. Progressive Web Apps (PWA) is a new technology to overcome search limitations with mobile devices and native applications designed and developed by Google (Tandel, S. S., \& Jamadar, A. 2018).

There are several previous studies related to this research. First, a study discusses automatic street lighting design based on solar panel power sources using ultrasonic, passive infrared, and LDR sensors (Wicaksono, M. F. 2018). Second, the research discusses the comparison of messaging protocols used in the last two decades (Naik, N. 2017). Third, the research discusses several solutions that will be used to secure communication channels, such as transport layer security or symmetric encryption (Dinculeană, D., \& Cheng, X. 2019). Fourth, a study discusses street lighting systems based on artificial neural networks (Yu et al. 2020). Fifth, the research discusses the implementation of IoT-based public street lighting systems (Kokilavani, 
M., \& Malathi, A. 2017). The difference between this study and the first one is the MQTT protocol used to transmit data from the gateway. The difference between this study and the second one is that there is a comparison between the MQTT, CoAP, AMQP, and HTTP protocols, whereas this study only uses the MQTT protocol. The difference between this study and the third one uses the value-to-HMAC method to maximize performance and ensure that the target node reads only data messages. In contrast, this study did not use this method. The difference between this study and the fourth study is that the street lighting system uses the Artificial Neural Network method, while this study does not use it. The difference between this study and the fifth study is that this study focuses on controlling the intensity of light by considering objects near the light. There is no use of the MQTT protocol, while in this study, using this protocol.

Therefore, this research aims to implement the Message Queuing Telemetry Transport (MQTT) protocol and the Progressive Web App (PWA) of the Internet of Things (IoT) based public street lighting system. The results obtained are the ease of monitoring lamp conditions and early detection of lamp problems. It has also been adjusted to previous studies, so the MQTT protocol is used for data transmission and uses PWA to integrate the monitoring system with cell phones. With this combination, monitoring and maintaining street lighting can be carried out more efficiently.

\section{METHOD}

The steps in this research are as follows:

1. Creating System Architecture.

According to the analysis that has been done, the functional requirements of this system are to use solar energy resources to support power. The device must be able to operate in an outdoor environment. The distance between lights is at least 10 meters, can communicate with various environmental conditions. The results of the analysis are then made in the system design. The system will be made consists of hardware and 
software. On the hardware, there is a solar panel to convert solar energy into electrical energy. A solar charger controller as a regulator of the battery charging voltage, a battery to store power, LED lights as street lighting, microcontrollers to process data, light sensors, motion sensors, current and voltage sensors, RTC, dimmer modules, LoRA modules, and GSM modules. Each lamp will send data from the lights' condition from the sensor to a concentrator as a data collection center. Communication from the lamp to the concentrator uses LoRa. Then the data from the concentrator is published using the MQTT protocol to the broker. Website applications and mobile apps will subscribe to the data by the specified topic. From these data, it can be turned into information in the form of each lamp's status, location, and condition. Besides, websites and mobile apps can adjust lights by turning on and off the lights remotely without going to the location. With these features, it is expected to be useful for officers to efficiently monitor and maintain street lighting. The system architecture for the tools to be built is in Figure 1.

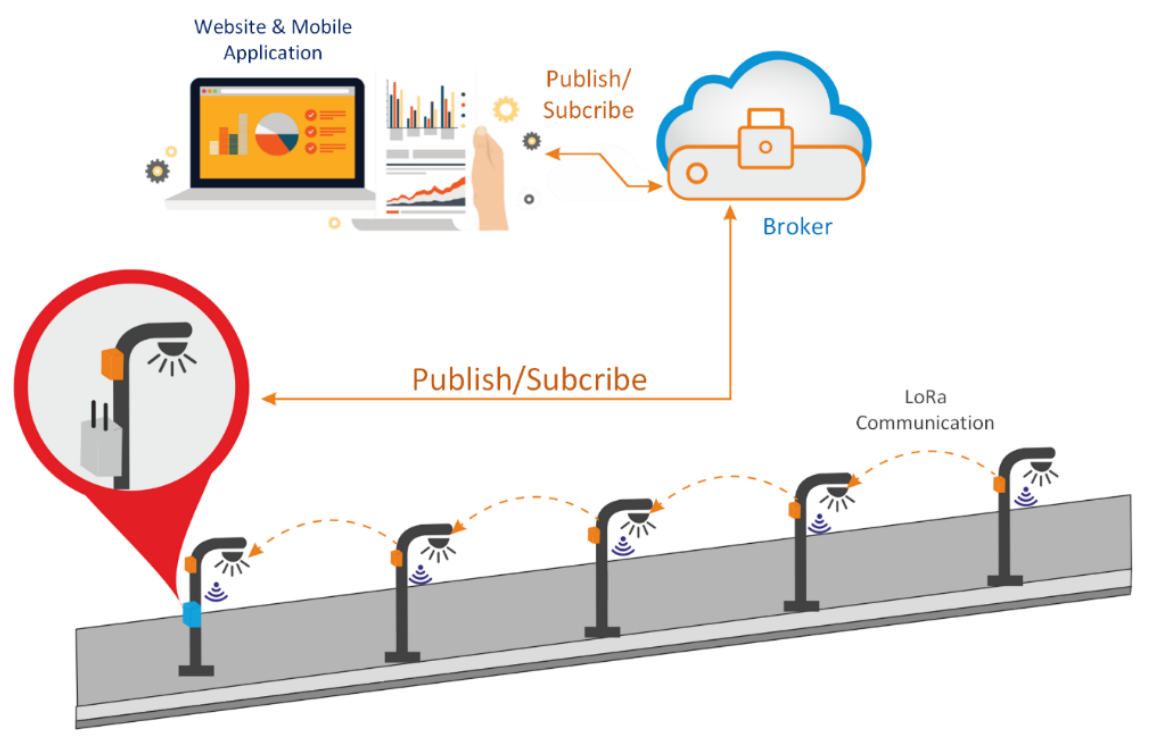

Figure 1 System Architecture 
2. Make a Block Diagram

In system design, it is necessary to make a block diagram to make the system easier. In the power source section, some devices function to provide power and regulate the work of lights. Some sensors detect the condition of the curve around the lamp on the sensor and control, such as light detection, people movement detection, time detection, and current and voltage working detection. There is a LoRa module for light communication to the concentrator and a GSM module for the concentrator communication to the broker in the communication section. The broker functions as the center for receiving data from concentrators compiled based on the specified topics. The broker can publish and subscribe to topics from the device and application in the application section using the website platform and mobile apps to display lighting conditions and manual control. The information displayed includes the lamp status, lamp usage graph, and the location of the lamp.

\section{Creating Hardware Scheme}

The implementation of the block diagram that has been made is hardware design. Each part of the hardware is connected to a connected circuit. To unite the circuit, it is necessary to make a schematic. Then made a PCB to connect every part of the electronic board. There can be seen all the hardware components described. Later, all electronic devices are stored in a device box that protects from various weather conditions in the field.

\section{Creating Software Design}

Software design is part of a web-based system that will be connected to the hardware device. To make this system or web, it is necessary to make a design. From there, the web appearance will be made according to what is intended. It can be seen as information from devices and users is explained and placed so that 
users easily understand it. The web page is built with progressive web application because it has the advantage that a reliable, fast, and engaging

\section{RESULTS AND DISCUSSION}

The results of this study are:

Based on the analysis that has been carried out, the functional requirements of this system are to be able to use solar energy sources as supporting power; the device must be able to:
a. operate in an outdoor environment
b. the distance between the lights is at least 10 meters
c. Can communicate various environmental conditions.

The results of the analysis are then made into system design. The system to be created consists of hardware and software. In the hardware section, there are:
a. solar panels to convert solar energy into electrical energy
b. solar charger controller as a battery charging voltage regulator
c. battery to save power

d. LED lights as street lighting

e. microcontroller to process data, light sensors, motion sensors, current and voltage sensors, RTCs, dimmer modules, LoRA modules, and GSM modules

f. Each lamp will send lamp condition data obtained from the sensor to the concentrator as the data collection center.

g. Communication from lamp to concentrator using LoRa.

h. Data from concentrators are published using the MQTT protocol to the broker. 
Website applications and mobile applications will subscribe to data according to the specified topic. This data can be converted into information in the form of each lamp's status, location, and condition. Additionally, websites and mobile apps can adjust lights by remotely turning lights on and off without going to the location. This feature is expected to be useful for officers in monitoring and maintaining street lighting efficiently.

In system design, it is necessary to make a block diagram to make the system easier. The system block diagram is shown in Figure 2. At the power supply section, a device functions to provide power and regulate the lights' work. Some sensors detect the curve's conditions around the lights on sensors and controls, such as light detection, people movement detection, time detection, and working current and voltage detection. There is a LoRa module for light communication to a concentrator and a GSM module for concentrator-to-broker communication in the communication section. The broker functions as a center for receiving data from concentrators arranged according to a specific topic. The broker can publish and subscribe to topics from the device and application. The application section uses a website platform and a mobile application to display lighting conditions and manual controls. Information displayed includes lamp status, lamp usage graph, and lamp location.

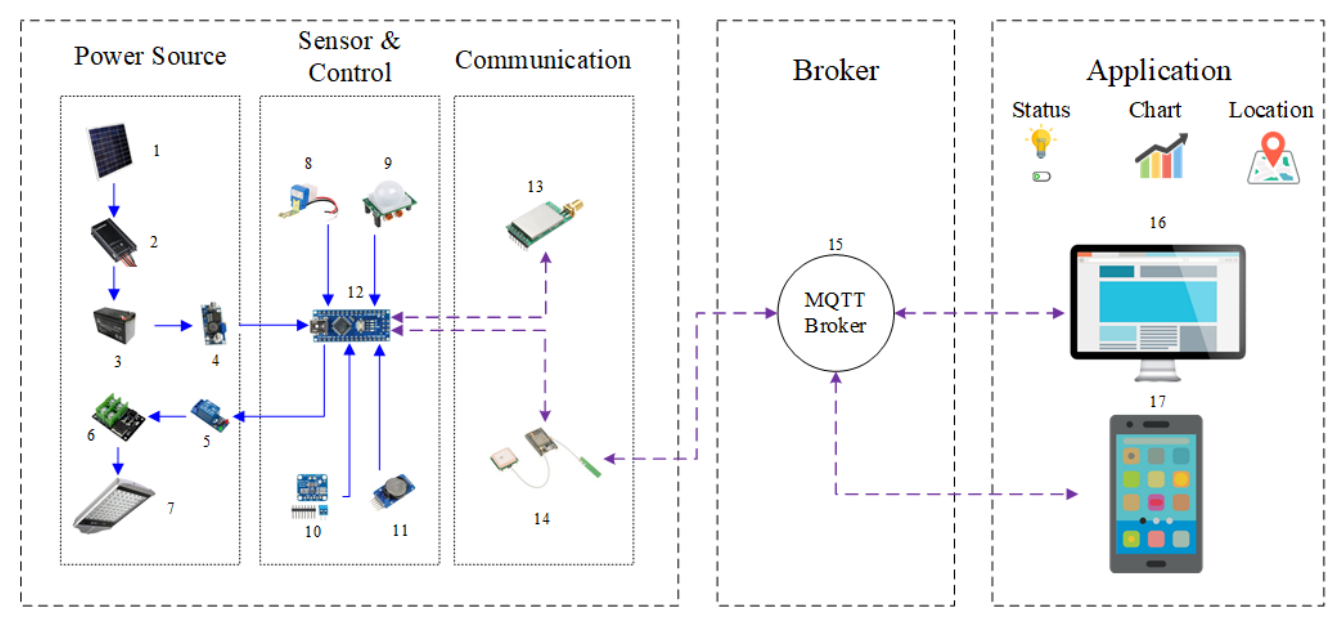

Figure 2 Block Diagram

The parts contained in the block diagram include Solar panel, Solar Charger Controller, Battery, Regulator, Relay, PWM Driver, LED Lamp, Photocell, Passive Infrared Sensor, 
Voltage and Current Sensor, Real-Time Clock, Microcontroller, LoRa Module, GSM Module, Broker, Website and Mobile Application. The functions of these parts are listed in Table 1 below:

Table 1 The function of each part

\begin{tabular}{|c|c|c|}
\hline No & Part & Function \\
\hline 1 & Solar Panel & Convert solar energy into electrical energy \\
\hline 2 & $\begin{array}{c}\text { Solar Charger } \\
\text { Controller }\end{array}$ & Regulate battery charging \\
\hline 3 & Battery & Saving power temporarily \\
\hline 4 & Regulator & Reduce the voltage from $12 \mathrm{VDC}$ to $5 \mathrm{VDC}$ \\
\hline 5 & Relay & Automatic switch to turn LED on and off \\
\hline 6 & PWM Driver & Set dimmer LED light with PWM \\
\hline 7 & LED Lamp & Street lighting \\
\hline 8 & Photocell & Day or night detection \\
\hline 9 & $\begin{array}{l}\text { Passive Infrared } \\
\text { Sensor }\end{array}$ & The motion of people detection \\
\hline 10 & $\begin{array}{c}\text { Voltage and Current } \\
\text { Sensor }\end{array}$ & $\begin{array}{l}\text { Measurement of voltage and current } \\
\text { working }\end{array}$ \\
\hline 11 & Real-Time Clock & Read the clock time \\
\hline 12 & Microcontroller & $\begin{array}{l}\text { Processing data sensor and manage of } \\
\text { communication }\end{array}$ \\
\hline
\end{tabular}




\begin{tabular}{|c|c|c|}
\hline 13 & LoRa Module & Convert TTL to LoRa communication \\
\hline 14 & GSM Module & Convert TTL to GPRS communication \\
\hline 15 & Broker & Data collection center \\
\hline 16 & Website & Display information and control lamp on \\
& Mobile Apps & Display information and control lamp on \\
17 & & mobile apps \\
\hline
\end{tabular}

Implementation of the block diagram that has been made is hardware design. Every piece of hardware is connected to the circuit it is connected to. To join the circuits, it is necessary to make a schematic. Then made a PCB to connect each part of the electronic board. The schematic can be seen in Figure 3. There can be seen all the hardware components described. Later, all these electronic devices are stored in a device box that protects from various weather conditions in the field. 


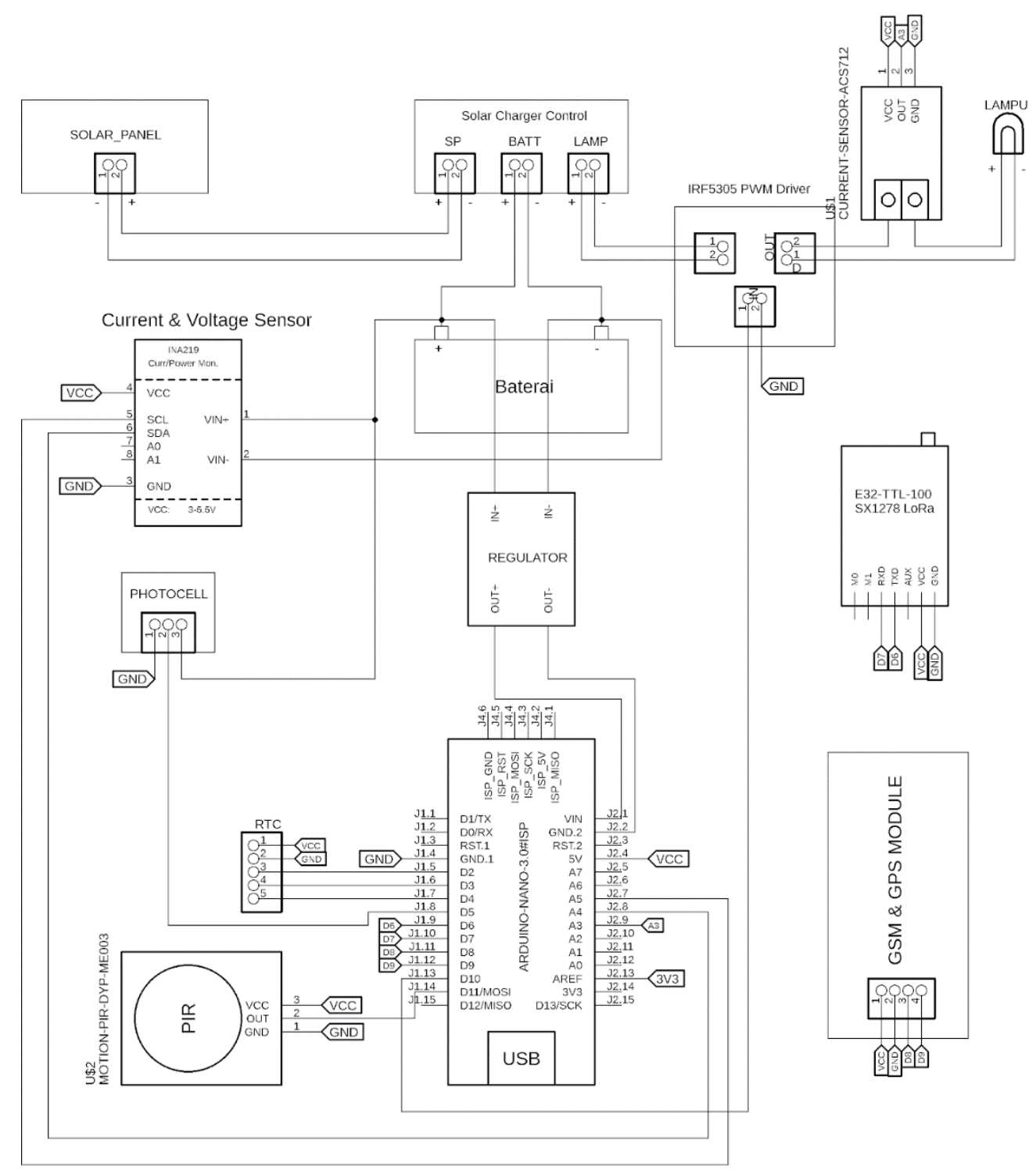

Figure 3 Hardware Scheme

This class diagram visualizes the structure of this program system explains the flow of each data in a table in the database. Figure 4 describes the classes that will later build a system to read data from the device to the web, and the data will be stored on the database. Besides, it will save from any access or use activities of this web system. 


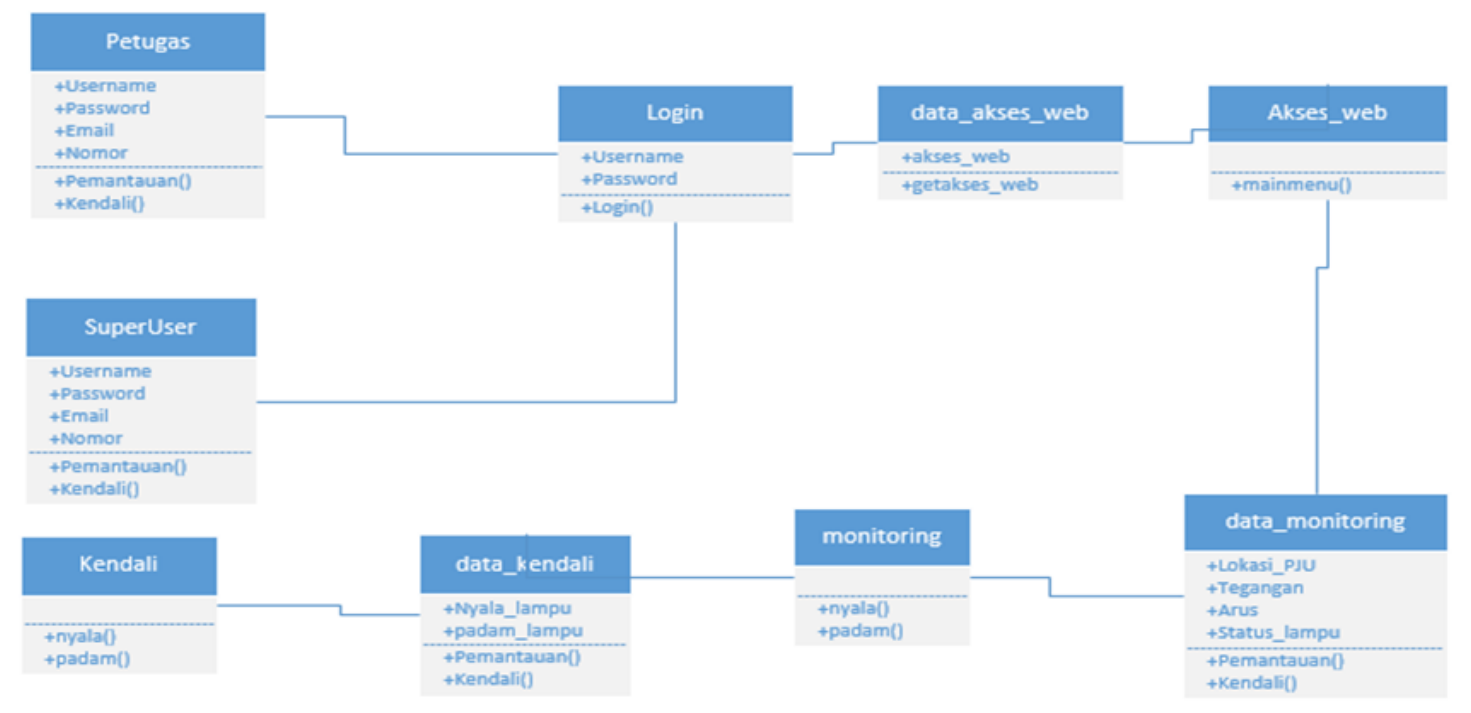

Figure 4 Class Diagram

Use case diagram states the visualization of interactions that occur between the user and the system. This diagram can be an illustration to explain the context of a system so that the system's boundaries are visible. Use case diagrams to describe the types of interactions between Smart Public Street Lighting lamps and web servers and administrators and system makers (Super Users). Figure 7 explains an IoT-based public street lighting system that sends data from each lamp to monitoring. It is also a control system of the street lighting using the MQTT protocol and an admin as monitoring. Control of each of the public street lighting through a monitoring system that is has been made by a Super User as the maker of this public street lighting monitoring and control system. 


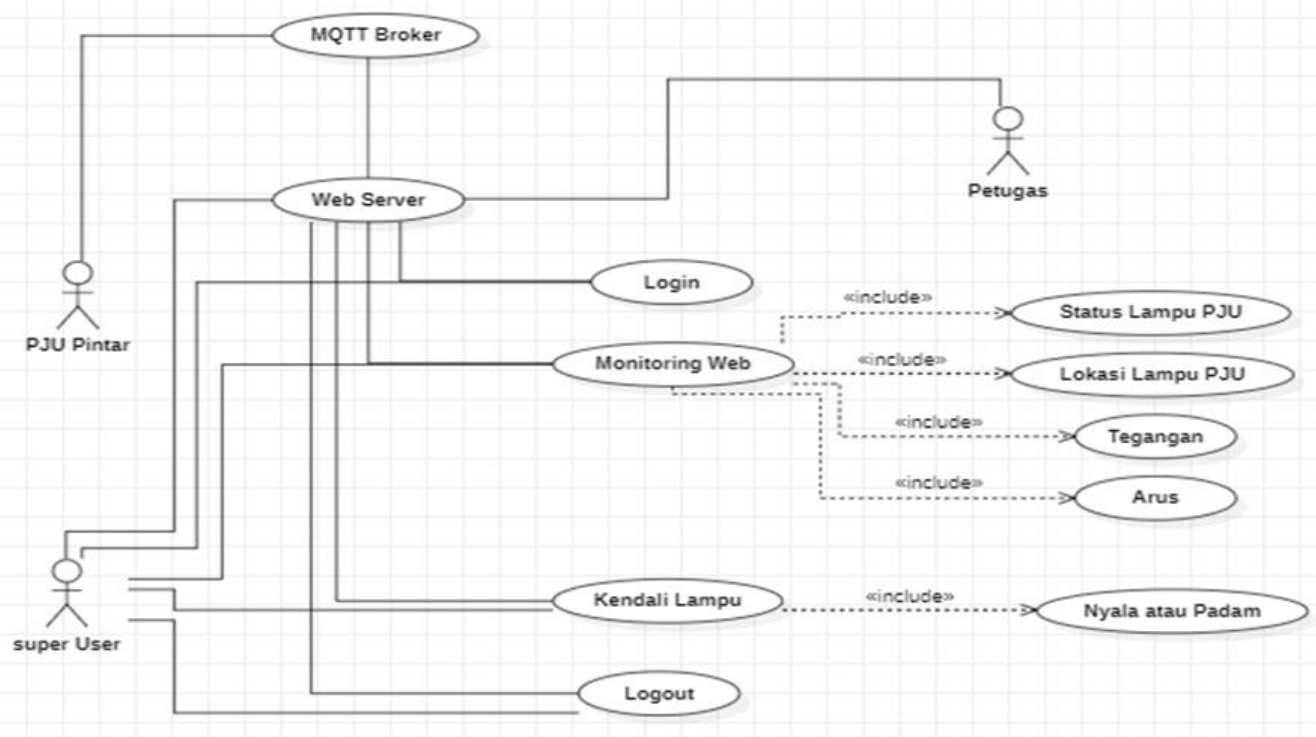

Figure 5 Use Case Diagram

Software design is part of a web-based system that will be connected to the hardware device. To make this system or web, it is necessary to make a design. The web appearance that will be made according to what is intended can be seen in Figure 6. It can be seen as information from devices and users is explained and placed so that users easily understand it. The web page is built with progressive web applications because it has reliable, fast, and engaging.

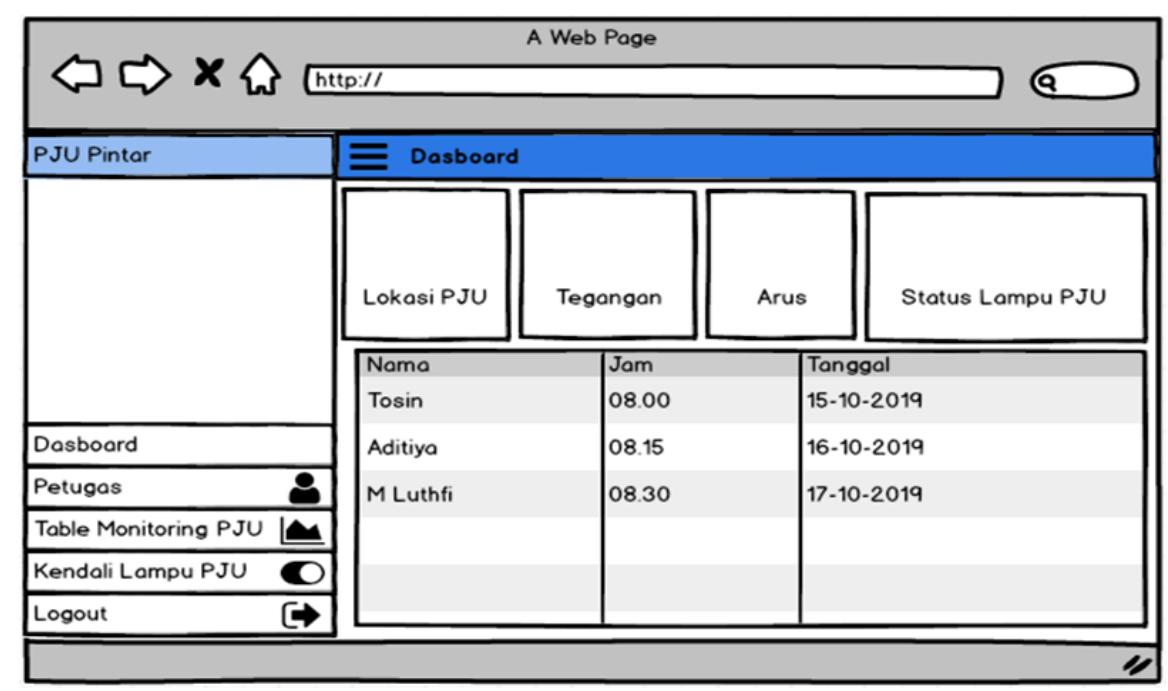

Figure 6 Web Design 
After all the steps are carried out, a tool and application can control street lighting. This research's impact is that street lighting monitoring and maintenance can be carried out more efficiently. Before the construction of this system, checking and maintaining street lighting has many obstacles, ranging from the lack of resources. It took a long time to check every public street lighting when the weather is not good too much risk to check street lighting. With this system, all the controls that are experienced can be handled as best as possible.

Compared with previous studies, the results are different due to differences in focus, as in the first study, the MQTT protocol used to transmit data from the gateway. There was no comparison between the protocol MQTT, COAP, AMQP, and HTTP in the second study. A third study using the value-to-HMAC, which is designed to maximize performance and ensure that only the target node reads the data message. The fourth study uses an artificial neural network, and fifth studies focus on controlling the light intensity of light by considering objects near the light (Soegoto et al., 2021).

Although there are many differences between this study and previous studies, previous research has helped complete this research. As from the first research, it can be learned how to use the MQTT protocol so that in this system, the application of this protocol can maximize system performance. Then from the second study, it was known how the advantages and disadvantages of each protocol. Therefore, it was decided to choose MQTT in this study with all its advantages and disadvantages. From the third research, it can be learned how the advantages of using the HMAC method, although, in the end, this study chose not to use this method because it was not suitable to be applied in this study. For the fourth research, Artificial Neural Networks can be studied in the construction of the system, how it is applied, how its advantages and disadvantages are. Even though the system built in this study has not implemented it, the hope is that it can use Artificial Neural Networks for further development. Furthermore, from the fifth research, it can be studied how the system controls objects near street lighting. In this study, we can develop ways of controlling and maintaining public street lighting so that the results are even more optimal. 


\section{CONCLUSION}

This research concludes that with the Message Queuing Telemetry Transport (MQTT) protocol, the data transmission process can be easier. Therefore, monitoring public street lighting can be carried out more effectively and efficiently, no longer having to come directly to the location to perform maintenance and not spend much time traveling. This research applies Internet of Things technology for easy monitoring and solar panels for efficient use of power. The topology used is centered in each cluster. Each cluster consists of several lights and a concentrator. Communication from the lamp to the concentrator uses LoRa, while the concentrator uses the internet network to publish data to the broker with the MQTT communication protocol. Websites and mobile apps will subscribe to the data and display it as information and control. The web page applies progressive web application technology so that web access is faster and can be run on mobile.

\section{ACKNOWLEDGEMENT}

Thank Universitas Komputer Indonesia for supporting this research. Thank you also to all those who have helped this research, starting from technical assistance or moral support, so this research can run smoothly and can get maximum results. 


\section{REFERENCES}

Buwana, D. P., Setiawidayat, S., \& Mukhsin, M. 2018. Sistem Pengendalian Lampu Penerangan Jalan Umum (PJU) Melalui Jaringan Internet Berbasis Android. JOINTECS (Journal of Information Technology and Computer Science), 3(3): 149-154.

Aung, N. S. M., \& Myint, Z. H. 2015. Design of stand-alone solar street lighting system with LED. International journal of scientific engineering and technology research, 3(17): $3518-3522$.

Ray, P. P. 2018. A survey on Internet of Things architectures. Journal of King Saud University-Computer and Information Sciences, 30(3): 291-319.

Tang, K., Wang, Y., Liu, H., Sheng, Y., Wang, X., \& Wei, Z. 2013. Design and implementation of push notification system based on the MQTT protocol. In 2013 International Conference on Information Science and Computer Applications (ISCA 2013): 116-119.

Tandel, S. S., \& Jamadar, A. 2018. Impact of progressive web apps on web app development. International Journal of Innovative Research in Science, Engineering and Technology, 7(9): 9439-9444.

Wicaksono, M. F. 2018. Lampu PJU Otomatis. Komputika: Jurnal Sistem Komputer, 7(1): $17-22$

Naik, N. 2017. Choice of effective messaging protocols for IoT systems: MQTT, CoAP, AMQP and HTTP. In 2017 IEEE international systems engineering symposium (ISSE): 1-7.

Dinculeană, D., \& Cheng, X. 2019. Vulnerabilities and limitations of MQTT protocol used between IoT devices. Applied Sciences, 9(5): 848.

Yu, D., Xu, X., Dong, M., Nojavan, S., Jermsittiparsert, K., Abdollahi, A., ... \& Pashaei- 
Didani, H. 2020. Modeling and prioritizing dynamic demand response programs in the electricity markets. Sustainable Cities and Society, 53: 101921.

Kokilavani, M., \& Malathi, A. 2017. Smart street lighting system using IoT. Int. J. Adv. Res. Appl. Sci. Technol, 3(11): 08-11.

Soegoto, E. S., Fauzi, F. A., \& Luckyardi, S. 2021. Internet of things for flood and landslide early warning. In Journal of Physics: Conference Series, 1764(1): 012190. 